\title{
LINHA DE CUIDADO ONCOLÓGICO EM UM AMBULATORIO ESPECIALIZADO EM IDOSOS
}

\section{Joana D’Arc Ricardo dos Santos, Andréa Aparecida Fonseca Monteiro, Bibiana Marie Semensato Povinelli, Eduardo Canteiro Cruz, Marcia Maiumi Fukujima}

\section{INTRODUÇÃO}

A Rede Hebe Camargo de Combate ao Câncer (RHCCC) foi inaugurada em 8 de março de 2013 no estado de São Paulo. A data foi escolhida por ser o Dia Internacional da Mulher e aniversário de Hebe Camargo, símbolo da luta contra o câncer. Em maio de 2013, o Ministério da Saúde instituiu a Política Nacional para a Prevenção e Controle do Câncer na Rede de Atenção à Saúde das Pessoas com Doenças Crônicas no SUS.

OBJETIVO: apresentar resultado do acompanhamento de casos da linha de cuidado oncológico em ambulatório de média complexidade do SUS especializado em idosos acima de 60 anos com especialidades predominantemente clínicas.

\section{DESENVOLVIMENTO}

Acompanhamento de casos por linha de cuidado foi implantado em julho de 2017. O fluxo da linha de cuidado oncológico se inicia com biópsia seguida do resultado com análise e diagnóstico pelo gerente da linha de cuidado (profissional enfermeiro). Se positivo, inserção na RHCCC e retorno em consulta de enfermagem e médica com encaminhamentos pertinentes. Acompanhamento por telefone ou por consultas em 10 dias, 3 e 6 meses. Esta linha se sobrepõe à linha de cuidado de geriatria com classificação de risco de mortalidade e perda de capacidade funcional - o alto risco é representado pela Síndrome Consumptiva, na qual há grande número de casos de câncer.

\section{RESULTADOS}

O ambulatório atendeu 5.893 casos novos no período de julho a dezembro/17 e 8.779 casos novos de janeiro a setembro/18. Foram inseridos 121 casos oncológicos (0,8\%) no período. O tempo médio entre o diagnóstico e agendamento foi de 65 dias em 2017 e 46 dias em 2018 (média 48 dias).
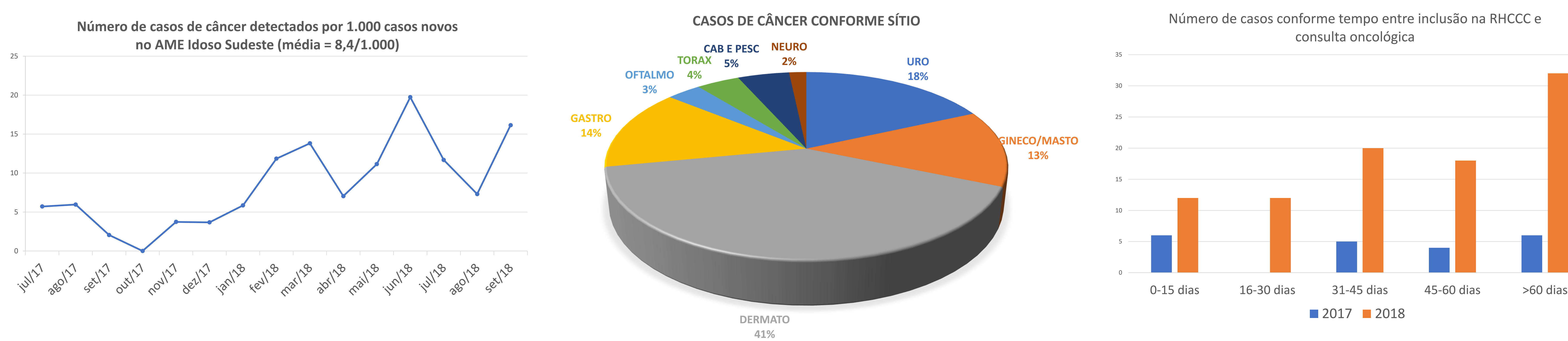

A meta de casos de câncer serem inseridos na rede e atendidos em até 60 dias tem sido alcançada a partir de 2018 , porém, $27 \%$ dos casos ainda leva 60 dias ou mais. Em 4 casos houve impossibilidade de contato e 1 caso seguiu acompanhamento na rede particular.

\section{CONCLUSÃO}

Contato e discussão com responsáveis pela RHCCC tem permitido ajustes de acessos a consultas especializadas e serviços. O atendimento ambulatorial na média complexidade precisa estar preparado para rápido diagnóstico e direcionamento de condutas nos casos de câncer nos idosos. 0 gerenciamento dos casos clínicos por linha de cuidado tem sido um bom modelo para diagnóstico e acompanhamento.

\section{REFERÊNCIAS}

http://www.saude.sp.gov.br/rede-hebe-camargo-de-combate-ao-cancer/homepage/acesso-rapido/historico-da-rhccc

PORTARIA № 874, DE 16 DE MAIO DE 2013 Ministério da Saúde

DECRETO № 62.394, DE 28 DE DEZEMBRO DE 2016 Governo do Estado de São Paulo 